\title{
Managed honeybee colony losses of the Eastern honeybee (Apis cerana) in China (2011-2014)
}

\author{
Chao $\mathrm{CHEN}^{1,2}$, Zhiguang LiU ${ }^{1,2}$, Yuexiong LuO ${ }^{3}$, Zheng $\mathrm{XU}^{4}$, Shunhai WANG ${ }^{5}$, \\ Xuewen $\mathrm{ZHANG}^{6}$, Rongguo $\mathrm{DAI}^{7}$, Jinglin $\mathrm{GAO}^{8}$, Xiao $\mathrm{CHEN}^{1}$, Haikun GuO ${ }^{1}$, \\ Huihua WANG ${ }^{1}$, Jiao TANG $^{1}$, Wei SHI ${ }^{1,2}$ \\ ${ }^{1}$ Institute of Apicultural Research, Chinese Academy of Agricultural Sciences, 1 Xiangshanbeigou, Haidian District, \\ Beijing 100093, China \\ ${ }^{2}$ Key Laboratory of Pollinating Insect Biology, Ministry of Agriculture, Beijing 100093, China \\ ${ }^{3}$ Guangdong Entomological Institute, Guangzhou, Guangdong, China \\ ${ }^{4}$ Guangxi Animal Husbandry Services, Nanning, Guangxi, China \\ ${ }^{5}$ Apiculture Management Center of Sichuan Province, Chengdu, Sichuan, China \\ ${ }^{6}$ Yunnan Academy of Agriculture Sciences, Honghe, Yunnan, China \\ ${ }^{7}$ Chongqing Academy of Animal Sciences, Chongqing, China \\ ${ }^{8}$ Chinese Academy of Tropical Agricultural Sciences Environment and Plant Protection Institute, Haikou, Hainan, China
}

Received 31 October 2016 - Revised 31 March 2017 - Accepted 26 April 2017

\begin{abstract}
Colony losses of managed honeybees have raised a major concern, and surveys of colony losses were conducted around the globe to understand the apicultural situation. Up to now, most studies have focused on the mortality of the Western honeybee (Apis mellifera); however, little is known about the mortality of its eastern counterpart - the Eastern honeybee (Apis cerana). Here, we report the survey results of A. cerana colony losses in three consecutive years (2011-2012, 2012-2013, and 2013-2014) in China. Colony losses were low overall (12.8\%, 95\% CI 11.9-13.7\%) but varied among years, provinces, and types of apiaries. We used generalized linear mixed effects models to estimate the effects of possible risk factors and found that queen problems (queenless or dronelaying queens) were associated with colony losses. Further analyses showed that differences in mortality among different types of apiaries may be contributable to the differences in queen problems. This is the first survey of colony losses of A. cerana.
\end{abstract}

\section{Colony losses / China / Honeybee / Apis cerana}

\section{INTRODUCTION}

Honeybees are important agricultural species as they provide not only pollination service which is valued more than $\$ 212$ billion (Gallai et al. 2009) but also ingredients for healthy human foods, such as honey, royal jelly, pollen, and propolis (Viuda-Martos et al. 2008). As a result, the decline in honeybees has raised tremendous con-

Corresponding author: W. Shi, shiweibri@ 126.com Manuscript editor: Stan Schneider cern (Moritz et al. 2010; vanEngelsdorp and Meixner 2010). As the result of an international effort called "Prevention of honey bee COlony LOSSes (COLOSS), a series of surveys have been conducted from around the globe toward understanding the situation of colony losses and elucidating possible causes, including Europe (Aston 2010; Charrière and Neumann 2010; Clermont et al. 2014; Gajger et al. 2010; Gray et al. 2010; Hatjina et al. 2010; Ivanova and Petrov 2010; Mutinelli et al. 2010; Topolska et al. 2010; Vejsnæs et al. 2010; van der Zee 2010; van der Zee et al. 2014), the USA (Lee et al. 2015; Seitz et al. 2015; Spleen et al. 2013; Steinhauer 
et al. 2014; vanEngelsdorp et al. 2010), South Africa (Pirk et al. 2014), China (Liu et al. 2016; van der Zee et al. 2012), and other areas (Brodschneider et al. 2010; Currie et al. 2010; van der Zee et al. 2012). The mortalities reported were high in general, with $7-30 \%$ for Europe, $22.5-35.8 \%$ for the USA, $29.6 \%$ for Africa, and $3.3-12.6 \%$ for China.

The surveys conducted so far have focused on the Western honeybee (Apis mellifera); however, colony losses of the other important honeybee species, the Eastern honeybee (Apis cerana), have not been reported. Apis cerana is native to Asia with a long history of managed beekeeping (Hepburn and Radloff 2011). In China, A. cerana beekeeping has begun since at least 1700 years ago. Nowadays, A. cerana is still kept in large quantity, estimated to be $\sim 2$ million in China alone. The lack of survey data on A. cerana colony losses is unsettling given the wide distribution of this species (Radloff et al. 2010) and the severe population decline in recent decades (Abrol 2013).

In general, $A$. cerana and $A$. mellifera has similar characteristics but with some noticeable distinctions (summarized in Park et al. (2015)). For example, A. cerana colonies are better in collecting scattered floral resources (Miyamoto 1958), have a lower minimum foraging temperature (Tan et al. 2012), and exhibit a stronger defense against hornets (Abrol 2006; Ono et al. 1995). Notably, as the natural host of Varroa destructor, A. cerana is resistant to the parasite after long term of host-parasite coevolution (Rath 1999). Therefore, it is possible that the rate and pattern of colony losses of $A$. cerana are different from those of $A$. mellifera.

To gain a better understanding of colony losses of $A$. cerana in China, we conducted a 3-year survey from 2011 to 2014 in six provinces of China. The goal of this study is to quantify and compare the rates of loss for different years, provinces, and different sizes of operations. In addition, we aim to explore the relationship between different management practices and mortality to identify management measures associated with high survival of colonies. This is the first survey of the colony losses of $A$. cerana.

\section{MATERIALS AND METHODS}

\subsection{Survey}

The questionnaire for the survey was designed based on the standard survey method for colony losses (van der Zee et al. 2013). The questions consisted of two sections: the survey for colony losses and the survey for management practices. The following questions were asked in the questionnaires:

Part 1: Losses

1. How many colonies did you have on October 1st?

2. How many of these colonies were lost during October 1st-April 1st?

Part 2: Management

3. How many times did you replace the queen?

4. Did you renew the combs?

5. Did you treat for varroa mites?

6. How many of the colonies experienced queen problems (queenless or drone-laying queens)?

7. How much honey was produced in your apiary (in kilograms)?

The purpose of the survey for management practices was to find whether certain practice can improve colony survival. Therefore, we did not include questions related to sacbrood virus because there are no prevalent management measures in preventing or treating for the pathogen. Furthermore, sacbrood disease was not prevalent in the six provinces during the surveyed periods. Instead, we included the question concerning the treatment of varroa mites as practiced by some beekeepers of $A$. cerana .

Questionnaires were sent to local beekeeping organizations at the end of each of the three surveyed periods (1 Oct 2011 to 1 Apr 2012, 1 Oct 2012 to 1 Apr 2013, and 1 Oct 2013 to 1 Apr 2014) and were distributed to beekeepers. Completed questionnaires were then collected by local beekeeping organizations, and answers were uploaded into our online databases (http://www.brpdb.com/).

\subsection{Statistics}

Data were retrieved from the online database. Data were first filtered for duplicates and invalid 
answers (number of colonies lost $>$ number of colonies in October 1st). Remaining data were used for calculation of overall loss rates, following the standard procedure outlined by van der Zee et al. (2013). Overall loss rates were calculated as the proportion of total number of colonies lost divided by total number of colonies, and percentage of colonies with queen problems were calculated as the proportion of colonies with queen problems divided by total number of colonies. Confidence interval (CI) was calculated using an intercept-only generalized linear model (GLM) with a quasi-binomial distribution and a logit link function. Beekeepers were categorized into parttime beekeepers (1-50 colonies), sideline beekeepers (50-200 colonies), and commercial beekeepers (200 or more colonies). Unlike other honeybee surveys (van der Zee et al. 2012, 2014; Lee et al. 2015; Seitz et al. 2015; Spleen et al. 2013; Steinhauer et al. 2014; vanEngelsdorp et al. 2010), we used 200 instead of 500 colonies as a threshold for commercial beekeepers, because, in general, only commercial beekeepers keep more than 200 colonies in their apiaries in China. Even by our standard, only 78 out of 937 (8.3\%) respondents can be categorized as commercial beekeepers in this survey (see Sect. 3).

Because of the hierarchical structure of the data, we used generalized linear mixed models (GLMMs) with binomial distribution to test the effects of potential risk factors on colony losses (van der Zee et al. 2014). GLMMs allow the incorporation of both fixed effects and random effects (Zurr et al. 2009). We included percentage of colonies with queen problems, honey production, frequency of requeening, varroa mite treatment, comb renewal, and apiary size as fixed effects, and year, province, and beekeepers as random effects in the model.

All calculations and analyses were done using R statistical software (R Core Team 2015), GLMMs analysis was performed using the "lme4" package (Bates et al. 2012).

\section{RESULTS}

\subsection{Overall national losses}

We received 937 valid responses from beekeepers in six provinces. In total, our 3-year survey included 93,220 colonies. The number of responses was 373 for 2011-2012, 332 for 20122013, and 232 for 2013-2014. Total number of colonies included in the survey was 35,608 for 2011-2012, 30,111 for 2012-2013, and 27,501 for 2013-2014. Of all the responses, 274 (29.2\%) reported no loss. Overall colony losses were low but varied among years (Table I). The 3year overall colony loss rate was $12.8 \%$ (95\% CI $11.9-13.7 \%$ ), with the highest annual losses in 2012-2013 (16.8\%; 95\% CI 15.1-18.6\%), significantly higher than that of the other years. The annual loss rate was lowest in 2011-2012 (9.2\%; 95\% CI 7.9-10.7\%) and intermediate in 20132014 (13.0\%; 95\% CI 11.6-14.5\%), significantly higher than that of 2011-2012.

\subsection{Colony losses by apiary size}

The numbers of part-time, sideline, and commercial beekeepers were 255 (27.2\%), 604 $(64.5 \%)$, and $78(8.3 \%)$, respectively (Table II). Total number of managed colonies was 9018 (9.7\%) for part-time beekeepers, 60,973 (65.4\%) for sideline beekeepers, and 23,229 (24.9\%) for commercial beekeepers. Part-time beekeepers reported a loss of $18.9 \%$ (95\% CI 16.8-21.2\%), with $26.7 \%(n=68)$ reported no loss. Sideline beekeepers reported a loss of $13.6 \%$ (95\% CI $12.4-14.8 \%)$, with $29.8 \%(n=180)$ reported no loss. Commercial beekeepers reported a loss of $8.3 \%$ (95\% CI $6.5-10.5 \%)$, with $33.3 \%(n=26)$ reported no loss. Based on the $95 \% \mathrm{CI}$, differences in 3-year mortalities among part-time $(95 \% \mathrm{CI}$ $16.8-21.2 \%$ ), sideline (95\% CI 12.4-14.8\%), and commercial beekeepers (95\% CI 6.5-10.5\%) were significant, with larger apiaries having lower mortality. For individual years, part-time beekeepers (95\% CI 15.8-22.4\%) have significantly higher mortality than sideline $(95 \%$ CI $7.4-$ $11.1 \%)$ and commercial beekeepers $(95 \% \mathrm{CI}$ 2.3-9.2\%) in 2011-2012. Sideline beekeepers (95\% CI 10.6-22.5\%) experienced significantly higher mortality than commercial beekeepers (95\% CI 7.0-12.6\%) in 2013-2014. Differences among different sizes of apiaries were not significant in 2012-2013; however, a general trend of lower colony losses in larger apiaries can be observed in all years. 
Table I. Reported 2011-2014 colony loss of A. cerana in China

\begin{tabular}{llllc}
\hline Period & $\begin{array}{l}\text { No. of } \\
\text { apiaries }\end{array}$ & $\begin{array}{l}\text { No. of colonies } \\
\text { in October sum }\end{array}$ & $\begin{array}{l}\text { No. of colonies in October } \\
\text { median (interquartile range) }\end{array}$ & $\begin{array}{l}\text { Overall loss (\%) } \\
{[95 \% \text { CI] }}\end{array}$ \\
\hline $2011-2014$ & 937 & 93,220 & $74(50-130)$ & $12.8(11.9-13.7)$ \\
$2011-2012$ & 373 & 35,608 & $70(46-120)$ & $9.2(7.9-10.7)$ \\
$2012-2013$ & 332 & 30,111 & $68(46-120)$ & $16.8(15.1-18.6)$ \\
$2013-2014$ & 232 & 27,501 & $60(83-150)$ & $13.0(11.6-14.5)$ \\
\hline
\end{tabular}

Patterns of among year variation of mortality were also different in different sizes of apiaries (Table II). For part-time beekeepers, annual colony losses were relatively stable, with losses of $18.8 \%$ (95\% CI $15.8-22.4 \%$ ), $20.0 \%$ (95\% CI $16.6-23.8 \%$ ), and $15.6 \%$ (95\% CI $10.6-22.5 \%$ ) in 2011-2012, 2012-2013, and 2013-2014, respectively. Annual colony losses varied more for sideline and commercial beekeepers, with losses of $9.1 \%$ (95\% CI $7.4-11.1 \%$ ), $17.4 \%$ (95\% CI $15.2-19.9 \%$ ), and $14.9 \%$ (95\% CI $13.2-16.8 \%$ ) for sideline beekeepers in 2011-2012, 20122013, and 2013-2014, respectively, and losses of $4.6 \%$ (95\% CI 2.3-9.2\%), $11.7 \%$ (95\% CI 7.8$17.4 \%$ ), and $9.4 \%$ (95\% CI 7.0-12.6\%) for commercial beekeepers in 2011-2012, 2012-2013, and 2013-2014, respectively. Among year mortality difference was significant for sideline beekeepers (Table II).

\subsection{Provincial losses}

Among the six provinces in our survey, Chongqing showed the lowest level of colony loss of $9.3 \%$ (95\% CI 7.5-11.3\%), significantly lower than that of Guangxi and Sichuan. Sichuan had the highest colony loss of $17.2 \%$ (95\% CI 12.9-22.7\%), but not significantly higher than other provinces except for Chongqing. The other four provinces, Guangdong (12.4\%; 95 CI 10.9-13.9\%), Guangxi (15.1\%; 95\% CI 12.7-17.8\%), Hainan (13.6\%; 95\% CI $11.2-16.5 \%)$, and Yunnan (13.6\%; 95\% CI $11.2-16.4 \%$ ), showed intermediate level of colony losses (Table III, Fig. 1).

Further examination of losses of the provinces for each year showed variation in annual losses for the provinces (Fig. 2a). Based on the 95\% CI, we observed significant among year

Table II. Reported 2011-2014 losses by apiary size in China

\begin{tabular}{lllllc}
\hline Period & $\begin{array}{l}\text { Operation } \\
\text { type }\end{array}$ & Number & $\begin{array}{c}\text { No. of colonies } \\
\text { in October sum }\end{array}$ & $\begin{array}{c}\text { No. of colonies in October } \\
\text { median (interquartile range) }\end{array}$ & $\begin{array}{l}\text { Overall loss (\%) } \\
{[95 \% \text { CI }]}\end{array}$ \\
\hline \multirow{2}{2}{$2011-2014$} & Part-time & 255 & 9018 & $36(28-45)$ & $18.9(16.8-21.2)$ \\
& Sideline & 604 & 60,973 & $85(65-130)$ & $13.6(12.4-14.8)$ \\
& Commercial & 78 & 23,229 & $260(230-300)$ & $8.3(6.5-10.5)$ \\
$2011-2012$ & Part-time & 118 & 4096 & $34(27-46)$ & $18.8(15.8-22.4)$ \\
& Sideline & 231 & 23,361 & $86(66-130)$ & $9.1(7.4-11.1)$ \\
& Commercial & 24 & 8151 & $290(230-335)$ & $4.6(2.3-9.2)$ \\
$2012-2013$ & Part-time & 103 & 3701 & $37(30-44)$ & $20.0(16.6-23.8)$ \\
& Sideline & 210 & 21,215 & $80(65-130)$ & $17.4(15.2-19.9)$ \\
& Commercial & 19 & 5195 & $250(217-310)$ & $11.7(7.8-17.4)$ \\
$2013-2014$ & Part-time & 34 & 1221 & $38(28-45)$ & $15.6(10.6-22.5)$ \\
& Sideline & 163 & 16,397 & $82(64-130)$ & $14.9(13.2-16.8)$ \\
& Commercial & 35 & 9883 & $254(232-295)$ & $9.4(7.0-12.6)$ \\
\hline
\end{tabular}


Table III. Reported 2011-2014 losses by province in China

\begin{tabular}{llllc}
\hline Province & $\begin{array}{l}\text { No. of } \\
\text { apiaries }\end{array}$ & $\begin{array}{l}\text { No. of colonies } \\
\text { in October sum }\end{array}$ & $\begin{array}{l}\text { No. of colonies in October } \\
\text { median (interquartile range) }\end{array}$ & $\begin{array}{c}\text { Overall loss (\%) } \\
{[95 \% \text { CI] }}\end{array}$ \\
\hline Guangdong $^{\text {Guangxi }}$ & 228 & 34,905 & $140(90-180)$ & $12.4(10.9-13.9)$ \\
Hainan $^{\text {Chongqing }}$ & 125 & 13,539 & $80(60-150)$ & $15.1(12.7-17.8)$ \\
Sichuan & 166 & 11,749 & $46(30-69)$ & $13.6(11.2-16.5)$ \\
Yunnan & 185 & 16,280 & $68(40-111)$ & $9.3(7.5-11.3)$ \\
\hline
\end{tabular}

${ }^{\text {a }}$ No data were collected for Guangxi in 2013-2014

differences for Guangdong, Guangxi, and Chongqing. Among year differences of losses were not significant for the other provinces. Trends of mortality change from 2011 to 2014 were also different for different provinces. In Yunnan, annual loss was highest in 2011-2012 and declines 2 years in a row in 2012-2013 and 2013-2014. Guangdong and Sichuan showed the highest losses in 2012-2013, whereas Chongqing experienced the lowest mortality in 2012-2013. Correlations between provincial annual losses further illustrate that patterns of changes in losses differed among provinces (Fig. 2b).

\subsection{Management practices associated with colony losses}

To explore potential risk factors underlying colony losses, we used GLMMs to access effects of potential risk factors, including percentage of colonies with queen problems (as a covariate; hereafter referred to as queen problems), honey production (as a covariate), frequency of requeening (as a covariate), varroa mite treatment (yes, no), comb renewal (yes, no), and apiary size (part-time, sideline, commercial). Using year, province, and beekeeper as random effects, we first screened the effect of these factors

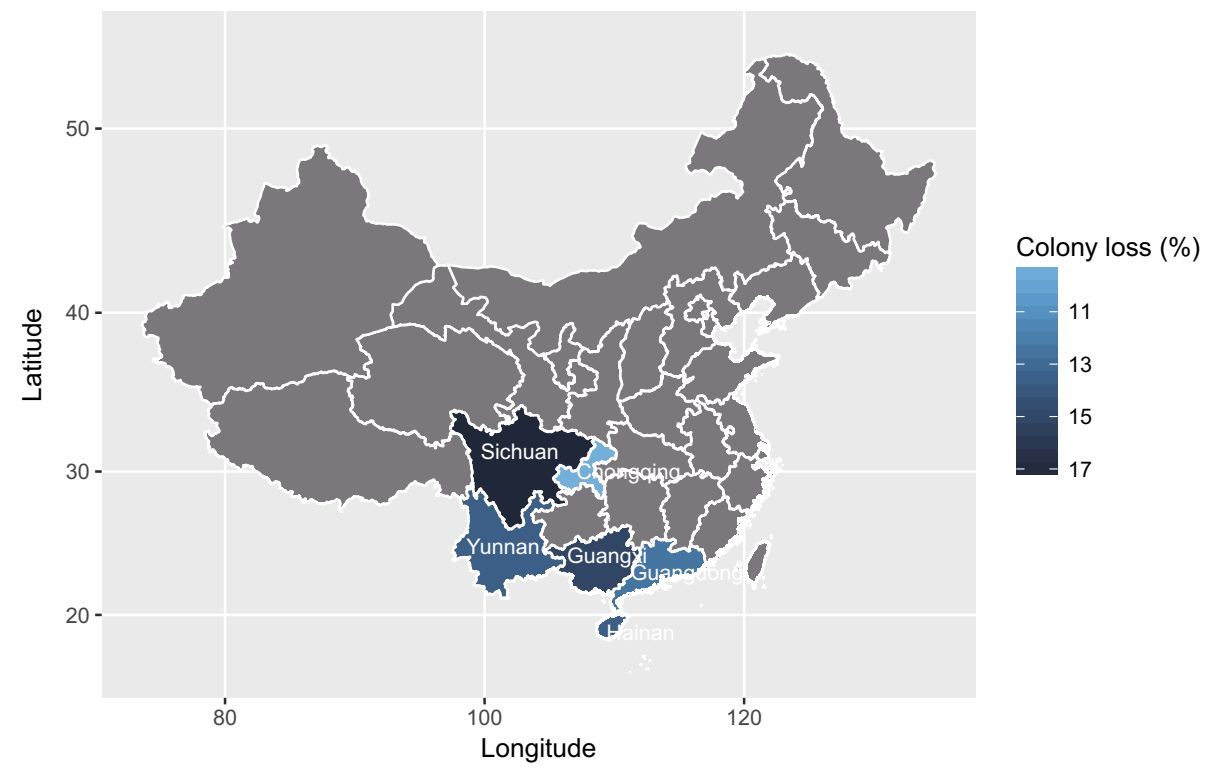

Figure 1. Overall provincial colony losses. 


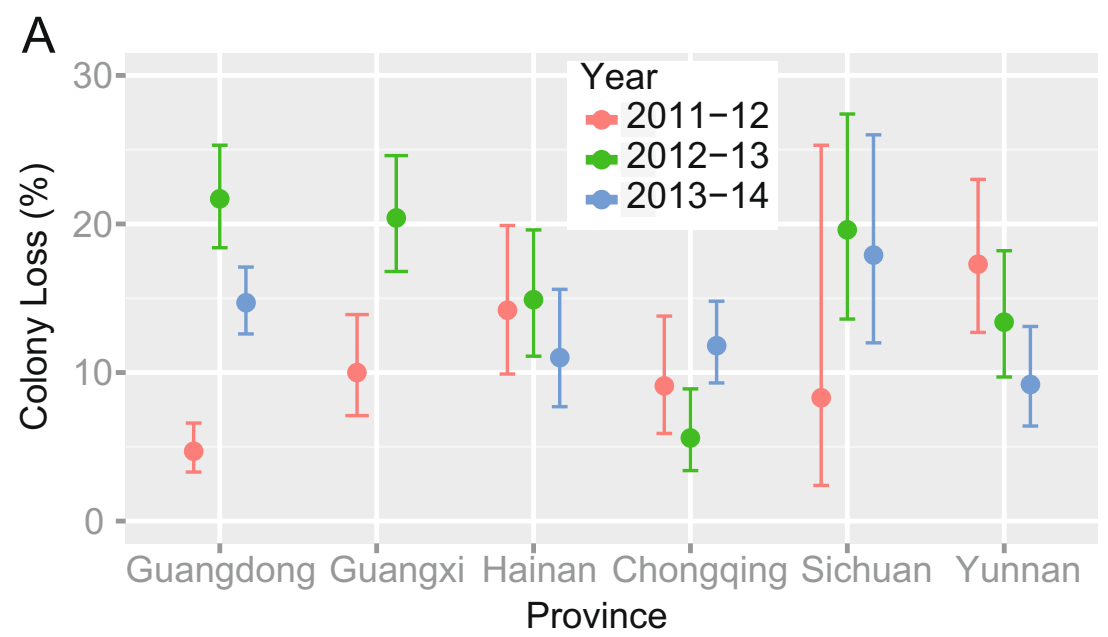

B Correlation of annual losses between provinces

\begin{tabular}{lccccc}
\hline & Guangdong & Hainan & Chongqing & Sichuan & Yunnan \\
\hline Guangdong & - & 0.068 & -0.476 & 0.960 & -0.568 \\
Hainan & & - & -0.909 & -0.213 & 0.783 \\
Chongqing & & & - & -0.213 & -0.453 \\
Sichuan & & & & - & -0.774 \\
Yunnan & & & & & - \\
\hline
\end{tabular}

Figure 2. Provincial colony losses. (a) Comparison of colony losses of the provinces for the year 2011-2012, 20122013, and 2013-2014. Means and 95\% confidence intervals are shown. (b ) Correlation of annual losses between provinces. No data were collected for Guangxi in 2013-2014.

individually and found significant effect of queen problems and apiary size on colony losses, while varroa mite treatment, comb renewal, honey production, or frequency of requeening did not have a significant effect. Next, we constructed a full model which included the two significant factors and the three random factors, in which apiary size was not significant, while queen problems remained significant. Likelihood ratio test to compare the models with and without apiary size confirmed that apiary size is not significant ( $p$ value $=0.9003$ ). The final model included only queen problems as fixed effect, and year, province, and beekeeper as random effects. Odds ratio for the risk of colony loss for queen problem is 1.37 , with $95 \% \mathrm{CI}$ of $(1.28,1.48)$. In addition, Fig. 3 shows that colony loss of an apiary was seldom lower than the percentage of colonies with queen problems, and the overall condition of queens in an apiary may set a lower limit of the colony loss.

\subsection{Queen problems, apiary sizes, and colony losses}

As shown above, differences in mortality among different sizes of apiaries were significant when tested singly, but not significant when queen problems were included, suggesting a possible relationship between them. We calculated the percentage of colonies with queen problems for part-time, sideline, and commercial beekeepers in different years (Fig. 4). Similar to colony losses, smaller apiaries tend to experience higher percentage of queen problems. Judging from the 95\% CI, queen problems were significantly higher for part-time beekeepers than for sideline and commercial beekeepers, and significantly lower for commercial beekeepers than for part-time and sideline beekeepers. In years where differences of colony losses among different sizes of apiaries were significant, differences in queen 


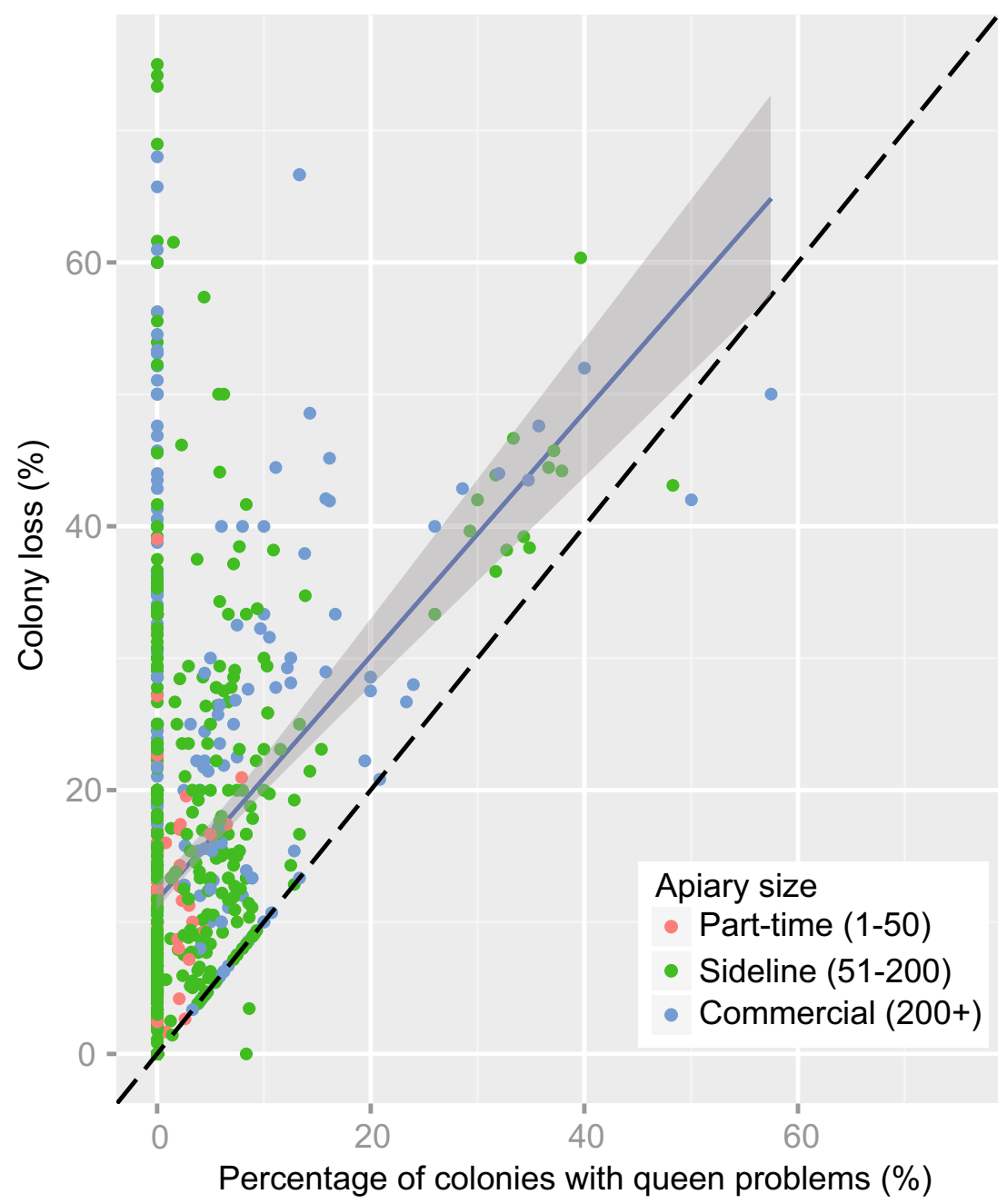

Figure 3. Colony loss and percentage of colonies with queen problems. The solid line represents the regression line, and the shaded area represents the confidence interval. The dash line represents the line where colony loss equals to percentage of colonies with queen problems, below which colony loss is lower than percentage of queen problems.

problems were also significant. This observation suggests an association among queen problems, apiary size, and colony losses.

\section{DISCUSSION}

The first survey of mortality for A. cerana reveals a low colony loss of $12.8 \%$, considerably lower than that of other countries. A loss of $12.8 \%$ in current study can be considered as acceptable by the beekeepers (Steinhauer et al. 2014).
The differences in mortality among provinces may be attributable to the differences in the environment, genetic composition, and/or genotype by environment interaction (Costa et al. 2012; Meixner et al. 2014; Büchler et al. 2014; Hatjina et al. 2014). Information on phenotypes and genetics of various geographic populations of $A$. cerana and possibly reciprocal translocation experiments are needed for further investigation.

Apiaries with higher percentage of queen problems also experienced higher losses. This result is consistent with findings by van der Zee et al. 

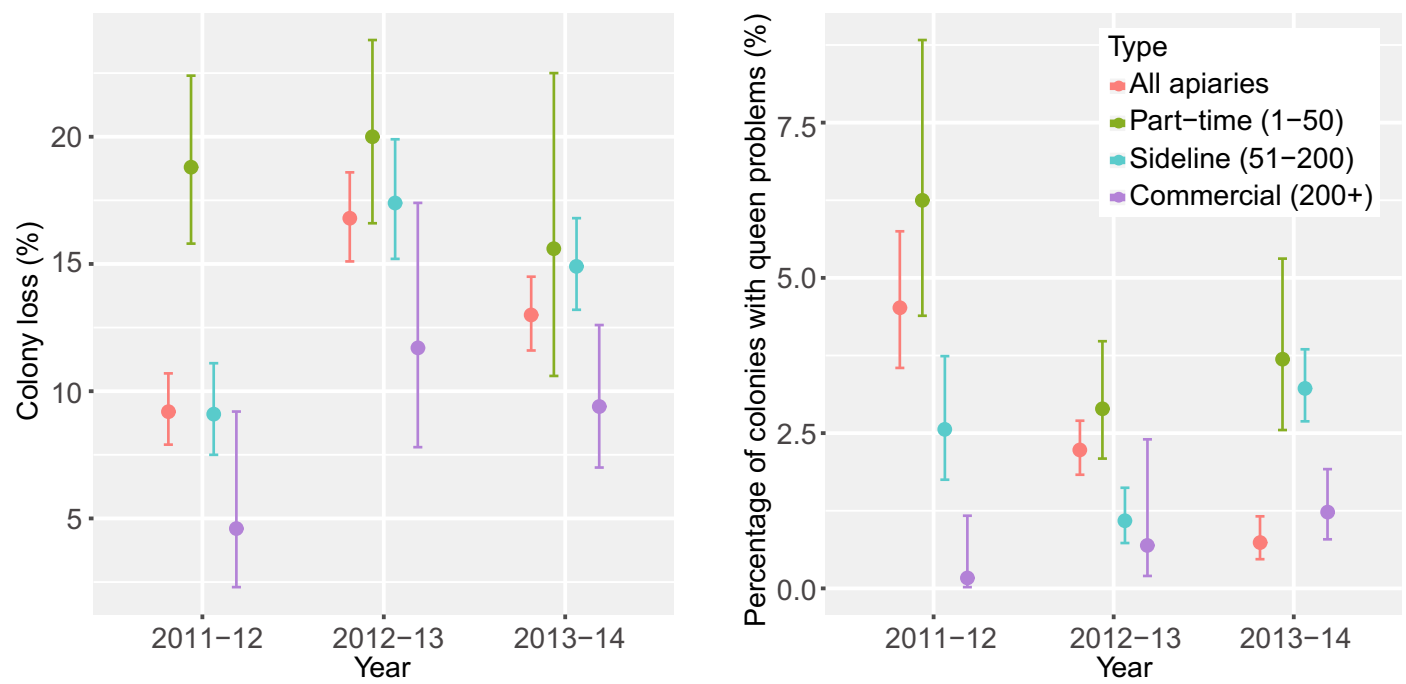

Figure 4. Colony losses (left $)$ and percentage of colonies with queen problems (right) for different sizes of apiaries overall and in the year 2011-2012, 2012-2013, and 2013-2014.

(2014). Queen problems may lead to weak colonies and thus high losses. In addition, queen problems can be an indication of colony problems (Collins and Pettis 2013; Pettis et al. 2004; Tarpy et al. 2012). Note that even though our survey shows an association between queen problems and colony losses, it does not imply a causal relationship. Carefully designed experiments are needed to confirm a causative explanation.

Differences in colony losses among different sizes of apiaries can be partially explained by the differences in the extent of queen problems. In general, larger apiaries tend to experience lower percentage of queen problems and lower losses. It is not clear what is causing the differences among different sizes of apiaries, and it will be interesting to explore this by adding more questions in the future regarding the differences among different types of apiaries, such as management and expertise.

It is not surprising that treatment of varroa mite did not make significant differences in colony losses. A. cerana is the natural host of varroa mite and is known to be resistant to the parasite. Our result further confirms that even though some beekeepers (261 out of 937 in our survey, 28\%) take measures to treat for varroa mite in A. cerana colonies, it may not be necessary. In addition, treatment of varroa mite increases the cost of management and can lead to side effect on the bees (Higes et al. 1999; Mattila et al. 2000; Melathopoulos et al. 2000; Rinderer et al. 1999) and chemical residuals in honeybee products (Wallner 1999). Therefore, beekeepers should be cautious when deciding whether to treat for varroa mite.

Several improvements can be made to our current survey. Firstly, the respondents in this survey may not represent all beekeepers as they were not chosen in a random way. Rather, surveys were distributed to attendees of local conferences and other events, and therefore biased toward the more active beekeepers who tend to involve more in activities hosted by local beekeeping organizations. Emphasis should be made on adopting additional ways of surveys in the future. Secondly, even though it is clear in our data that queen problems is associated with colony losses, it is unclear what exact factor may be contributing to the queen problems. Detailed questions of queen problems, such as age of queens (Genersch et al. 2010; van der Zee et al. 2014) and source of queens, can be included in future surveys. Thirdly, several biotic and abiotic factors related to colony losses were identified in recent years (reviewed in Vanbergen and the Insect Pollinators Initiative (2013)); questions concerning these factors may also yield valuable information and can be added to the survey. Lastly, as mentioned 
above, differences in adaptation of modern beekeeping methods may play an important role in colony losses; related questions may provide additional information for the understanding of honeybee colony losses.

\section{ACKNOWLEDGEMENTS}

This work was supported by the Chinese Academy of Agricultural Sciences (The Agricultural Science and Technology Innovation Program, grant number CAASASTIP-2017-IAR), the earmarked fund for Modern Agroindustry Technology Research System (grant number CARDS-45-KXJ1), and China Postdoctoral Science Foundation (grant number 2015M581222). We thank Xuefeng Zheng from Guangdong Entomological Institute, Junjun $\mathrm{Hu}$ from Guangxi Apiculture Management Center of Guangxi Zhuang Autonomous Region, Yusheng Yu and Huanxian Lu from Yunnan Academy of Agriculture Science, Junfeng Liu from Chinese Academy of Tropical Agricultural Sciences Environment and Plant Protection Institute, and the staff working on the project from Apiculture Management Center of Sichuan Province, Chongqing Academy of Animal Sciences, for their assistance in conducting this survey. We appreciate the provincial beekeeping organizations for their effort in making the survey among beekeepers, as well as numerous beekeepers participating in this survey. We also thank Leon YE for building and managing the online database.

Contributions ZL and WS conceived this research; ZL, YL, ZX, SW, XZ, RD, JG, XC, HG, HW, and JT conducted the survey and collected the data; CC performed the analysis; $\mathrm{CC}$ and WS wrote the paper.

\section{OPEN ACCESS}

This article is distributed under the terms of the Creative Commons Attribution 4.0 International License (http://creativecommons.org/licenses/by/4.0/), which permits unrestricted use, distribution, and reproduction in any medium, provided you give appropriate credit to the original author(s) and the source, provide a link to the Creative Commons license, and indicate if changes were made.

Pertes dans les colonies de l'abeille asiatique (Apis cerana ) élevées en Chine (2011-2014)
Verluste bei imkerlich gehaltenen Honigbienenvölkern (Apis cerana) in China (2011-2014)

\author{
Bienenvolk-Erhebung / China / Honigbienen / Apis \\ cerana
}

\section{REFERENCES}

Abrol, D. P. (2006). Defensive behaviour of Apis cerana F. against predatory wasps. J. Apic. Sci. 50, 39.

Abrol, D. P. (2013). Asiatic honeybee Apis cerana: Biodiversity conservation and agricultural production. Dordrecht: Springer Netherlands Available at: http://edepot. wur.nl/275982.

Aston, D. (2010). Honey bee winter loss survey for England, 2007-8. J. Apic. Res. 49, 111-112.

Bates, D., Maechler, M., Bolker, B. (2012). lme4: Linear mixed-effects models using S4 classes.

Brodschneider, R., Moosbeckhofer, R., Crailsheim, K. (2010). Surveys as a tool to record winter losses of honey bee colonies: a two year case study in Austria and South Tyrol. J. Apic. Res. 49, 23-30.

Büchler, R., Costa, C., Hatjina, F., Andonov, S., Meixner, M. D., et al. (2014). The influence of genetic origin and its interaction with environmental effects on the survival of Apis mellifera L. colonies in Europe. J. Apic. Res. 53, 205-214.

Charrière, J.-D., Neumann, P. (2010). Surveys to estimate winter losses in Switzerland. J. Apic. Res. 49, 132-133.

Clermont, A., Eickermann, M., Kraus, F., Georges, C., Hoffmann, L., Beyer, M. (2014). A survey on some factors potentially affecting losses of managed honey bee colonies in Luxembourg over the winters 2010/ 2011 and 2011/2012. J. Apic. Res. 53, 43-56.

Collins, A. M., Pettis, J. S. (2013). Correlation of queen size and spermathecal contents and effects of miticide exposure during development. Apidologie 44, 351-356.

Costa, C., Lodesani, M., Bienefeld, K. (2012). Differences in colony phenotypes across different origins and locations: evidence for genotype by environment interactions in the Italian honeybee (Apis mellifera ligustica)? Apidologie 43, 634-642.

Currie, R. W., Pernal, S. F., and Guzmán-Novoa, E. (2010). Honey bee colony losses in Canada. J. Apic. Res. 49, 104-106

Gajger, I. T., Tomljanović, Z., Petrinec, Z. (2010). Monitoring health status of Croatian honey bee colonies and possible reasons for winter losses. J. Apic. Res. 49, 107-108.

Gallai, N., Salles, J.-M., Settele, J., Vaissière, B. E. (2009). Economic valuation of the vulnerability of world agriculture confronted with pollinator decline. Ecol. Econ. 68, 810-821. doi:10.1016/j.ecolecon.2008.06.014.

Genersch, E., von der Ohe, W., Kaatz, H., Schroeder, A., Otten, C., et al. (2010). The German bee monitoring project: a long term study to understand periodically 
high winter losses of honey bee colonies. Apidologie 41, 332-352.

Gray, A., Peterson, M., Teale, A. (2010). An update on recent colony losses in Scotland from a sample survey covering 2006-2008. J. Apic. Res. 49, 129-131.

Hatjina, F., Bouga, M., Karatasou, A., Kontothanasi, A., Charistos, L., et al. (2010). Data on honey bee losses in Greece: a preliminary note. J. Apic. Res. 49, 116-118.

Hatjina, F., Costa, C., Büchler, R., Uzunov, A., Drazic, M., et al. (2014). Population dynamics of European honey bee genotypes under different environmental condidtions. J. Apic. Res. 53, 233-247.

Higes, M., Meana, A., Suarez, M., Llorente, J. (1999). Negative long-term effects on bee colonies treated with oxalic acid against Varroa jaocbsoni Oud. [brood development]. Apidologie 30, 289-292

Hepburn, H. R., Radloff, S. E. (Eds.). (2011). Honeybees of Asia. Springer Science \& Business Media.

Ivanova, E. N., Petrov, P. P. (2010). Regional differences in honey bee winter losses in Bulgaria during the period 2006-9. J. Apic. Res. 49, 102-103.

Lee, K. V., Steinhauer, N., Rennich, K., Wilson, M. E., Tarpy, D. R., et al. (2015). A national survey of managed honey bee 2013-2014 annual colony losses in the USA. Apidologie 46, 292-305.

Liu, Z., Chen, C., Niu, Q., Qi, W., Yuan, C., Su, S., et al. (2016). Survey results of honey bee (Apis mellifera) colony losses in China (2010-2013). J. Apic. Res. 55, 29-37. doi:10.1080/00218839.2016.1193375.

Mattila, H. R., Otis, G. W., Daley, J., Schulz, T. (2000). Trials of apiguard, a thymol-based miticide part 2. Non-target effects on honey bees. Am. Bee J. 140, 68-70.

Meixner, M. D., Büchler, R., Costa, C., Francis, R. M., Hatjina, F., et al. (2014). Honey bee genotypes and the environment. J. Apic. Res. 53, 183-187.

Melathopoulos, A. P., Winston, M. L., Whittington, R., Smith, T., Lindberg, C., et al. (2000). Comparative laboratory toxicity of neem pesticides to honey bees (Hymenoptera: Apidae), their mite parasites Varroa jacobsoni (Acari: Varroidae) and Acarapis woodi (Acari: Tarsonemidae), and brood pathogens Paenibacillus larvae and Ascophaera apis . J. Econ. Entomol. 93, 199-209.

Miyamoto, S. (1958). Biological studies on japanese bees$X$. Differences in flower relationships between a japanese and an european honeybees. Sci. Rep. Hyogo Univ. Agric. 3, 99-107.

Moritz, R. F. A., de Miranda, J., Fries, I., Conte, Y. L., Neumann, P., Paxton, R. J. (2010). Research strategies to improve honeybee health in Europe. Apidologie 41, 227-242.

Mutinelli, F., Costa, C., Lodesani, M., Baggio, A., Medrzycki, P., et al. (2010). Honey bee colony losses in Italy. J. Apic. Res. 49, 119-120.

Ono, M., Igarashi, T., Ohno, E., Sasaki, M. (1995). Unusual thermal defence by a honeybee against mass attack by hornets. Nature 377, 334-336.
Park, D., Jung, J. W., Choi, B.-S., Jayakodi, M., Lee, J., et al. (2015). Uncovering the novel characteristics of Asian honey bee, Apis cerana, by whole genome sequencing. BMC Genomics 16, 1-16. doi:10.1186/1471-2164-16-1.

Pettis, J., Collins, A., Reg. Wilbanks, Mark F. Feldlaufer (2004). Effects of coumaphos on queen rearing in the honey bee, Apis mellifera. Apidologie 35, 605-610.

Pirk, C. W., Human, H., Crewe, R. M., VanEngelsdorp, D. (2014). A survey of managed honey bee colony losses in the Republic of South Africa-2009 to 2011. J. Apic. Res. 53, 35-42.

R Core Team (2015). R: A language and environment for statistical computing. Vienna, Austria: R Foundation for Statistical Computing Available at: http://www.Rproject.org/.

Radloff, S. E., Hepburn, C., Hepburn, H. R., Fuchs, S., Hadisoesilo, S., et al. (2010). Population structure and classification of Apis cerana . Apidologie 41, 589-601.

Rath, W. (1999). Co-adaptation of Apis cerana Fabr. and Varroa jacobsoni Oud. Apidologie 30, 97-110.

Rinderer, T. E., de Guzman, L. L, Lancaster, V. A., Delatte, G. T., Stelzer, J. A. (1999). Varroa in the mating yard. I. The effects of Varroa jacobsoni and apistan on drone honey bees. Am. Bee J., Available at: http://agris.fao. org/agris-search/search.do?recordID=US1999004883 [Accessed February 1, 2016].

Seitz, N., Traynor, K. S., Steinhauer, N., Rennich, K., Wilson, M. E., et al. (2015). A national survey of managed honey bee 2014-2015 annual colony losses in the USA. J. Apic. Res. 54, 292-304.

Spleen, A. M., Lengerich, E. J., Rennich, K., Caron, D., Rose, R., et al. (2013). A national survey of managed honey bee 2011-12 winter colony losses in the United States: results from the Bee Informed Partnership. J. Apic. Res. 52, 44-53.

Steinhauer, N. A., Rennich, K., Wilson, M. E., Caron, D. M., Lengerich, E. J., et al. (2014). A national survey of managed honey bee 2012-2013 annual colony losses in the USA: results from the Bee Informed Partnership. J. Apic. Res. 53, 1-18.

Tan, K., Yang, S., Wang, Z.-W., Radloff, S. E., Oldroyd, B. P. (2012). Differences in foraging and broodnest temperature in the honey bees Apis cerana and A. mellifera . Apidologie 43, 618-623.

Tarpy, D. R., Keller, J. J., Caren, J. R., Delaney, D. A. (2012). Assessing the mating "health" of commercial honey bee queens. J. Econ. Entomol. 105, 20-25.

Topolska, G., Gajda, A., Pohorecka, K., Bober, A., Kasprzak, S., et al. (2010). Winter colony losses in Poland. J. Apic. Res. 49, 126-128.

Vanbergen, A. J., and the Insect Pollinators Initiative (2013). Threats to an ecosystem service: pressures on pollinators. Front. Ecol. Environ. 11, 251-259.

vanEngelsdorp, D., Jr, J. H., Underwood, R. M., Pettis, J. S. (2010). A survey of honey bee colony losses in the United States, fall 2008 to spring 2009. J. Apic. Res. 49, 7-14. 
vanEngelsdorp, D., Meixner, M. D. (2010). A historical review of managed honey bee populations in Europe and the United States and the factors that may affect them. J. Invertebr. Pathol. 103, S80-S95.

Vejsnæs, F., Nielsen, S. L., Kryger, P. (2010). Factors involved in the recent increase in colony losses in Denmark. J. Apic. Res. 49, 109-110.

Viuda-Martos, M., Ruiz-Navajas, Y., Fernández-López, J., Pérez-Álvarez, J. a. (2008). Functional Properties of Honey, Propolis, and Royal Jelly. J. Food Sci. 73, R117-R124.

Wallner, K. (1999). Varroacides and their residues in bee products. Apidologie 30, 235-248.

van der Zee, R. (2010). Colony losses in the Netherlands. J. Apic. Res. 49, 121-123.

van der Zee, R., Brodschneider, R., Brusbardis, V., Charrière, J.-D., Chlebo, R., et al. (2014). Results of international standardised beekeeper surveys of colony losses for winter 2012-2013: analysis of winter loss rates and mixed effects modelling of risk factors for winter loss. J. Apic. Res. 53, 19-34.

van der Zee, R., Gray, A., Holzmann, C., Pisa, L., Brodschneider, R., et al. (2013). Standard survey methods for estimating colony losses and explanatory risk factors in Apis mellifera. J. Apic. Res. 52, $1-36$.

van der Zee, R., Pisa, L., Andonov, S., Brodschneider, R., Charrière, J.-D., et al. (2012). Managed honey bee colony losses in Canada, China, Europe, Israel and Turkey, for the winters of 2008-9 and 2009-10. J. Apic. Res. 51, 100-114.

Zurr, A. F., Ieno, E. N., Walker, N. J., Saveliev, A. A., Smith, G. M. (2009). Mixed effects models and extensions in ecology with R. Springer, New York. 